\title{
Apresentação
}

\section{Transformações científicas e tecnológicas e implicações econômico-sociais}

SONIA K. GUIMARÃES

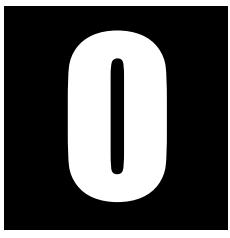

dossiê que ora apresentamos aos leitores do periódico Sociologias tem como tema central as transformações em curso desde as décadas finais do século XX e que se manifestam em diferentes dimensões, no âmbito da ciência, da tecnologia e da inovação, com implicações, em especial, na economia, colocando em destaque a configuração de um novo paradigma de desenvolvimento econômico-social, em que conhecimento, tecnologia, inovação e internacionalização tornam-se fatores cruciais para a criação de riqueza. As transformações científicas e tecnológicas atuais podem ser consideradas revolucionárias, visto que alteram a dinâmica da produção de riqueza e demais esferas da sociedade: capacidades intelectuais tornam-se mais relevantes para o desenvolvimento econômico do que capacidades físicas ou recursos naturais; bens "intangíveis" ou "informacionais" aumentam sua participação relativa na composição do Produto Interno Bruto (PIB), em detrimento de bens "tangíveis"; cresce de forma significativa, mundialmente, o número de patentes, resultado de aumento da atividade de pesquisa e desenvolvimento (P\&D) e da produção de novos conhecimentos. Novos setores econômicos com base na informática, na biologia molecular, na nanotecnologia, 
entre outras áreas científicas são criados; o número crescente de patentes concedidas a universidades sugere a importância do emprego da ciência básica para a produção de bens e serviços.

Nessa perspectiva, o escopo e a articulação dos cinco artigos que integram este dossiê subsidiam reflexões para uma discussão abrangente, abordando tópicos que buscam ampliar a compreensão acerca de desafios institucionais, organizacionais e socioculturais face às demandas impostas pelo paradigma acima referido, assim como, em relação às respostas e práticas de atores centrais dessa nova configuração do desenvolvimento econômico-social - ciência (universidades e instituições de pesquisa), agentes públicos e empresas.

Em termos gerais, os artigos examinam aspectos particulares, intrínsecos à natureza dos fenômenos emergentes, como a análise do comportamento econômico e da ação empreendedora intensiva em conhecimento, considerando a imersão da conduta estratégica dos agentes (Mocelin e Azambuja); a governança e sua aplicação às dinâmicas de coordenação da comunidade científica (Balbachevsky); a estratégia dos EUA no desenvolvimento de aliança público-privado, em que laboratórios públicos de pesquisa contribuem para fortalecer esforços de inovação do setor privado (Keller, Block e Negoita); o papel da inovação no desenvolvimento local e regional (Ramella) e a articulação entre processos de inovação e de inclusão social e o contexto territorial (Carrillo, Gomis e Bensusán).

Promover o desenvolvimento de um país depende hoje, principalmente, de sua capacidade de se integrar ao novo ciclo econômico, buscando estreitar o fosso que o separa da fronteira tecnológica, contando com a participação de agentes e atores distintos dos que produziram a riqueza dos séculos XIX e XX. Tal esforço exige capacitação elevada dos agentes em geral, além de envolvimento em um processo constante.de aprendizagem. 
Ainda em contraste com o século XX - marcado pela importância e o poder do capitalismo industrial sustentado por grandes empresas as últimas décadas do mesmo século evidenciam mudanças significativas no padrão de organização econômica em economias maduras (e que se difundem mundialmente), com presença e importância econômicas crescentes do empreendedorismo intensivo em conhecimento. Em razão desse crescimento, o tema do empreendedor inovador, praticamente ignorado pela economia neoclássica, voltou a ser vivamente discutido na tentativa de compreender a natureza e as motivações desse agente econômico e as consequências sociais que daí emergem. Nessa categoria, surge também o cientista-empreendedor, fruto de transformações na produção do conhecimento - como ocorre, por exemplo, na biotecnologia, cujo conhecimento produzido apresenta potencialidade comercial imediata.

O ressurgimento do empreendedorismo foi considerado por Neff et al. (2005) a verdadeira novidade da chamada "nova economia", visto que, ao contrário do padrão de emprego do mundo industrial do século $X X$, que se caracterizava pela estabilidade, o empreendedor inovador da chamada "nova economia" enfrenta riscos e incertezas em troca de projetos desafiadores, maior autonomia e satisfação em atividades de trabalho.

Pesquisas realizadas junto a empreendedores inovadores em Porto Alegre, Brasil, em meados dos anos 2000 - ocasião de grande demanda do mercado por esse tipo de profissional com ofertas de condições salariais e de trabalho atraentes - constatou-se objetivamente o peso das variáveis "escolha por riscos e incertezas" e "experiências desafiadoras, maior autonomia e realização no trabalho". Os ganhos monetários eram percebidos como consequência e não como meta. Os novos valores impunham-se em detrimento da estabilidade e segurança de um emprego bem remunerado em grandes empresas, públicas ou privadas, em ambiente de trabalho sem estímulos criativos. (Guimarães; Azambuja, 2010). 
Esses dados sugeriam a possibilidade de uma "mudança cultural" em matéria de atividade de trabalho, considerando comportamento, valores e objetivos de profissionais qualificados.

Que fatores socioeconômicos e/ou subjetivos estão relacionados ao comportamento dos empreendedores?

O tema do empreendedorismo é abordado, neste dossiê, no artigo de Mocelin e Azambuja. Os autores discutem diferentes perspectivas que tentam compreender o fenômeno e buscam identificar fatores que favorecem a emergência do empreendedorismo intensivo em conhecimento. Em oposição às abordagens que, segundo os autores, compreendem o fenômeno como respostas a condicionantes externos de ordem político-institucional - a "inovação emana de um processo sustentável e durável de inter-relações entre a ciência e o mercado, mediadas por políticas governamentais de Ciência, Tecnologia e Inovação" -, eles propõem a necessidade de ir além e privilegiar aspectos intrínsecos à ação empreendedora, no intento de compreender o sentido que orienta a ação do agente empreendedor, ou seja, o domínio da ação guiada por uma disposição subjetiva - "um processo mental imaginativo" - baseada em cálculos prévios que avaliam o potencial de valorização econômica e social.

A compreensão do fenômeno "empreendedorismo inovador" desenvolve-se em meio a debates e controvérsias. Contudo, como afirma Deutschmann (2009, p. 2; 4), "In spite of the centrality of the latter (entrepreneur) for modern societies a satisfactory conceptualization of the entrepreneur as an agent of change is still lacking in the social sciences... economic sociology still has no satisfactory solution for this problem." Cabe destacar que Deutschmann, seguindo Schumpeter, destaca no caráter do empreendedor seu papel de agente transformador/inovador/ criador. Dessa forma, critica tanto a perspectiva weberiana que atribui racionalidade à ação do empreendedor, quanto a perspectiva estrutural, 
que enfatiza o conceito de embeddedness. Em relação à primeira, afirma que conquanto o empreendedor atua sob condições de incerteza, ele seria incapaz de calcular vias para alcançar fins a partir de determinados meios; ao contrário da racionalidade, Deutschamann destaca a criatividade e a intuição. Em relação à perspectiva estrutural, a crítica se faz a partir da pergunta "How can the entrepreneur be a 'socially embedded' actor and a 'revolutionary of the economy' (Schumpeter) at the same time?" (Deutschmann, 2009, p. 4).

Esse é um tema que deverá se tornar cada vez mais relevante tanto na Sociologia como na Economia, considerando-se a próxima revolução que está às nossas portas - a chamada 4ạa. revolução industrial, em que os humanos serão substituídos por robôs e pela Inteligência Artificial em grande parte das atividades hoje existentes. Homens e mulheres terão que reinventar e criar novas atividades que se tornem imprescindíveis à sociedade e, ao mesmo tempo, necessitem da criatividade humana.

Se a presença do empreendedor inovador constitui a novidade do contexto econômico atual, outra novidade trata-se da necessidade da empresa (embora mantendo-se como lócus da inovação), de integrar-se a uma rede de inter-relações constituída por diferentes agentes sociais como a definida pelo modelo denominado "hélice tríplice" que se baseia na relação entre universidade, governo e empresas (Etzkowitz, 2008); ou a do chamado "Modo 2" de produção do conhecimento em que "[...] a closer integration of the process of discovery with that of fabrication [...] in which [...] institutional differences between, say, universities and industry, seem to be less and less relevant" (Gibbons et al., 1994, p. 19; 30).

Nessa rede de agentes sociais, as universidades são cada vez mais demandadas a participar de externalidades para contribuir não apenas na solução de problemas que dependem do suporte de conhecimento científico, como aquecimento global, segurança alimentar, envelhecimento 
populacional, dentre outros, mas também, em razão da complexidade, custos e riscos da pesquisa na atualidade e do curto ciclo de vida das inovações. Em consequência, as universidades têm sido pressionadas a transformar suas estruturas organizacionais, competências e estratégias, a fim de responder a problemas mais amplos, rompendo com a tradição do modelo humboldtiano - centrado na separação rígida entre academia e interesses econômicos e da sociedade.

O artigo de Balbachevsky aborda essa questão, a partir da análise das transformações no modelo de universidades contemporâneas - marcado pela dinâmica de valores da comunidade científica - em direção a um novo modelo - que se abre a demandas do ambiente externo. Segundo a autora, tais mudanças resultam tanto da expansão massiva dessas instituições, ocorrida no século XX, como de demandas sociais no sentido de que as universidades contribuam de forma mais efetiva para que o conhecimento produzido seja mobilizado para apressar o processo de desenvolvimento regional e/ou nacional, assim como a solução de problemas que afetam a vida cotidiana de populações e do planeta. A autora discute o conceito de governança e sua aplicação às dinâmicas de coordenação da comunidade científica, face às transformações no modo de produção do conhecimento. A autora conclui que, independentemente de pressões externas, o novo perfil da universidade resulta também de movimentos internos à ciência, em consequência da emergência de novos campos de conhecimento e da reconfiguração do modo de produção do conhecimento, o que se refletiria em tensões no modelo de governança das ciências e das universidades. A segunda parte do artigo busca aplicar essa análise ao exame da experiência brasileira, com foco específico nos desenvolvimentos recentes do aparato institucional de coordenação da ciência no Brasil.

O outro ator relevante do sistema de inovação seria o Estado. Como estratégia para reduzir a distância dos países que se encontram afastados 
da fronteira tecnológica, o Estado busca implementar políticas públicas de apoio e de investimentos à ciência, tecnologia e inovação, bem como expansão do empreendedorismo intensivo em conhecimento.

Intervenções públicas voltadas a impulsionar o crescimento ou apoiar setores específicos têm sido tema recorrente de debates, em especial, em países em desenvolvimento que se veem diante de defasagens tecnológicas que os obrigam ao esforço de tentar reduzir rapidamente tal defasagem. A maioria dos países hoje em desenvolvimento chegou ao patamar em que se encontra a partir de decisiva intervenção estatal. Essa estratégia, que se tornou dominante desde os anos 1930, começa hoje a ser questionada.

Esse questionamento parece oportuno, visto que o momento histórico é muito distinto daquele em que foi gerado. Não se trata apenas de reduzir a questão, simplificando-a por meio da oposição estado versus mercado; de fato, estes não se excluem, ao contrário, são complementaridades. Importa distinguir diferenças na natureza da ação governamental.

$\mathrm{O}$ artigo de Keller et al., neste dossiê, ilustra bem o sentido das afirmações acima, ao evidenciar a forma variada e descentralizada que caracteriza o apoio estatal ao setor privado inovador, nos EUA. Keller et al. abordam a questão sobre incentivos governamentais à inovação com foco em um dos inúmeros programas de colaboração - o acordo "Work for Others" (WFO) - que estabelece contratos entre laboratórios científicos governamentais e empresas privadas, permitindo a estas o acesso a pesquisas, consultoria e a equipamentos, mediante pagamento. Ao examinar o fenômeno, os autores contribuem para desfazer equívocos muito difundidos, de que a economia americana prescinde da ação do Estado, em especial, na esfera de estímulos aos desenvolvimentos tecnológico e de inovação. Contudo, chamam atenção os autores para aspectos particulares do tipo de ação do estado norte-americano, distinguindo-a de 
casos de intervenção na área de inovação e da tecnologia, em outros países. A intervenção do governo norte-americano, segundo Keller et al., constitui ampla gama de programas e políticas governamentais (militares e não-militares) que se realizam por meio de um conjunto de mecanismos que opera de forma dinâmica, descentralizada e bastante diversificada. Diferenciam-se, portanto, de iniciativas centralizadoras, em que prevalece a razão burocrática que, muitas vezes, caracteriza a natureza da intervenção em muitos países emergentes. Ao abordarem a ação do Estado em favor do desenvolvimento tecnológico, fica clara a especificidade da ação governamental no caso norte-americano, muito diferente do que ocorre em alguns países, inclusive no Brasil, onde não apenas, o Estado é o principal agente de financiamento à inovação, mas o faz de forma centralizada e nem sempre transparente.

O caso de empréstimos com juros subsidiados concedidos (período 2009-2015) pelo Banco de Desenvolvimento Econômico e Social (BNDES) a empresas lucrativas e de grande porte (que não poderiam ser contempladas com empréstimos subsidiados segundo normas de um banco de desenvolvimento), foi considerado um caso típico de "capitalismo de laços" ou "capitalismo de compadrio" e, portanto, sem benefícios para a sociedade. Estudos mostram que as empresas beneficiadas pelo BNDES não investiram em projetos intensivos em conhecimento, nem em projetos para o aumento da produtividade, ou em estratégias de modernização - estratégias obrigatórias para que o país enfrente os desafios do novo padrão de desenvolvimento (Almeida; Schneider, 2012; Guimarães, 2016).

Conclui-se que a natureza das intervenções do Estado depende do contexto político-social e institucional em que estão inseridas.

À medida em que conhecimento e inovação tornam-se a chave para o crescimento econômico, regiões que contam com os ativos demandados (infraestrutura, instituições de ensino superior, centros de pesquisa, 
centros tecnológicos, pessoal qualificado, quadro institucional) e que forem capazes de mobilizá-los de forma eficiente (circulação de informação e conhecimentos) estarão habilitadas a enfrentar os desafios da globalização e da inovação com sucesso, capazes de atrair e reter talentos. A partir dessa perspectiva, as noções de aglomeração geográfica, desenvolvimento local, cluster inovador (tributária das formulações de Alfred Marshall sobre "distritos industriais") voltam a assumir destaque no debate sobre desenvolvimento econômico conduzido pelo processo de inovação, visto que a dimensão territorial, nesse sentido, constitui-se em ator coletivo indispensável ao processo de inovação e que por sua capacidade de reduzir a incerteza, adquire importância estratégica, ao transformar regiões em fatores chave na construção de vantagens competitivas.

O artigo de Ramella, neste dossiê, aborda o tema acima sob a perspectiva da "geografia da inovação", com foco no caso italiano. Este último foi extensivamente estudado, em especial, nos anos 1990, considerado exemplo de "desenvolvimento regional", com base na realidade empresarial da chamada "Terceira Itália", que deu origem à perspectiva que destaca as relações entre empresa, inovação e território. Nesta abordagem, supõe-se que a produção de inovação depende de sistemas complexos e abertos de interação e de bens coletivos locais, tangíveis e intangíveis (infraestrutura e conjunto de instituições sólidas), incorporados ao território, representados pela cooperação de múltiplos atores (dentre outros, universidades, centros de pesquisa, capital humano, outras empresas, serviços avançados), em ambiente que favoreça a difusão do conhecimento para a inovação.

Segundo o autor, a investigação realizada com empresas altamente inovadoras corrobora a tese sobre a importância da relação inovação e território: as empresas de alta tecnologia estudadas concentravam-se em locais favorecedores à inovação; com elevado percentual de dispêndio 
em pesquisa e desenvolvimento tecnológico, que operavam em mercados altamente competitivos; com bom desempenho econômico. O autor traz à reflexão uma contribuição relevante, ao destacar que nem todas as empresas se beneficiam dos recursos disponíveis em um território, assim como, nem todas as regiões são capazes de explorar os recursos tangíveis e intangíveis de que dispõem para promover a inovação. Sua conclusão é que além de fatores estruturais, há que considerar fatores como agência, que definem a estratégia de ação tanto da empresa como da região, assim como a capacidade de estabelecer colaborações externas.

Outra novidade que já é evidente no novo paradigma, mas que deverá estender-se significativamente - dependendo de pressões das forças sociais - é a relação entre inovação e inclusão.

Esse tema é abordado, neste dossiê, por Carrillo, Gomis e Bensusán que discutem a relação entre inovação e inclusão social, destacando a relevância do conceito de "inovação inclusiva", no sentido de integrar a variável "inclusão social" como eixo constituinte da compreensão do processo de inovação, de maneira que a ênfase em inovação como base dos processos de desenvolvimento econômico não se limite às ideias de eficiência e competitividade das empresas, mas também, se estenda a necessidades de grupos sociais excluídos. Os autores partem de uma investigação que tem como unidades de análise empresas multinacionais localizadas no México. Concluem que o número de empresas multinacionais com desempenho inovador e inclusivo é bastante limitado. Interessante notar que a tese sobre a relação inovação e território, tão bem ajustada à realidade italiana como o demonstra Ramella em seu artigo, neste dossiê, apresentaria limites no caso de empresas multinacionais localizadas no México. Segundo Carrillo, Gomis e Bensusán: mais da metade das EMNs investigadas (57\%) localizavam-se em regiões do país com níveis elevados de desenvolvimento científico e tecnológico (CTI). Sabe-se que 
a influência do território não se faz apenas pela presença de CTI - outros fatores econômicos sociais e culturais são necessários. Sabe-se, também, que as EMNs tendem a realizar atividades de $P \& D$ que geram inovações em âmbito doméstico. Talvez, os critérios de inovação e inclusão devam ser mais bem negociados por agentes responsáveis em países receptores.

Se é verdade que inovação e inclusão social ainda constituem relações incipientes em empresas multinacionais, no contexto de países em desenvolvimento como os da América Latina, o mesmo parece não acontecer em outras situações em que inovação e inclusão são valores bastante difundidos. Forbes/Insights, a unidade de pesquisa da Forbes Media, divulgou o Relatório Global Diversity and inclusion Fostering Innovation Through a Diverse Workforce, (julho, 2011) em que apresenta resultados de pesquisa realizada em grandes empresas multinacionais localizadas em todos os continentes (Américas, Ásia-Pacífico, Europa, Oriente Médio e África). Os respondentes foram 321 executivos, responsáveis por programas sobre diversidade e inclusão das empresas em que atuam - grandes empresas globais com receitas anuais superiores a US\$ 500 milhões, sendo que $40 \%$ dos respondentes trabalhavam para empresas com faturamento anual de US\$ 5 bilhões ou mais.

Resumindo os resultados, destaca-se que praticamente a totalidade dos respondentes concordaram que mais importante do que constituir uma força de trabalho heterogênea, trata-se de contar com uma força de trabalho constituída com base na diversidade e na inclusão (gênero, etnicidade, cor, idade, orientação sexual e pessoas com necessidades especiais) considerados fatores determinantes para impulsionar a inovação, fomentar a criatividade e orientar estratégias empresariais no que se refere a novas ideias, novos serviços e novos produtos o que, segundo os respondentes, tenderia a favorecer a empresa quanto a vantagens competitivas no mercado. 
Vários programas com foco na diversidade e inclusão foram relatados como, por exemplo: o programa desenvolvido pela Intel que visa a incorporar maior número de mulheres e pessoas pertencentes a outras "minorias" nos programas STEM (Ciência, Tecnologia, Engenharia e Matemática); o programa de quatro anos com recursos de US \$ 100 milhões laçado pela AT\&T (2008) para enfrentar a crise de abandono escolar, visando a oferecer aos alunos apoio e ferramentas de que necessitassem para permanecer na escola.

Gênero, etnia e raça foram as áreas mais focadas pelas empresas, embora programas com foco em pessoas com necessidades especiais, diferentes etapas da vida (idade) e orientação sexual também tenham sido contemplados.

Independentemente das experiências acima referidas, o uso de tecnologias como a Internet tem demonstrado real contribuição para a inclusão social, considerando-se as múltiplas possibilidades de acesso hoje existentes à informação, comunicação e conhecimento à grande parte das pessoas de praticamente todas as sociedades. O alcance à informação, comunicação e conhecimento abrange diferentes áreas e disciplinas, desde ensino à distância incluindo cursos ministrados em universidades de prestígio internacional nos mais diferentes locais e regiões do globo, até acesso a atividades culturais as mais diversas.

Os temas abordados brevemente nesta apresentação poderão ser aprofundados com a leitura dos artigos que integram esse dossiê. Os autores estrangeiros que participam desse dossiê são pesquisadores especialistas no tema e integram grupos de pesquisas em três diferentes regiões do globo: Matthew Keller, Fred L. Block e Marian Negoita, são pesquisadores norte-americanos e abordam aspectos relacionados à realidade do país que está na fronteira do desenvolvimento tecnológico mostrando o papel do estado no processo de inovação de empresas privadas; 
Francesco Ramella dedica-se à análise de aspectos da realidade italiana, que é muito particular e ilustrativa por ser uma economia de renda alta, em que a produção inovadora não corresponde à fronteira tecnológica; Jorge Carrillo, Redi Gomis e Gabriela Bensusán, são pesquisadores mexicanos e examinam situações que, embora particulares da região, são mais próximas da realidade brasileira. No caso dos autores brasileiros, Elisabeth Balbachevsky contribui com questão que tem sido pouco abordada pela Sociologia, no Brasil, ou seja, o conceito de governança e sua aplicação na coordenação da comunidade científica. Daniel Mocelin e Lucas Azambuja desenvolvem o debate sobre inovação a partir de uma perspectiva sociológica por excelência, em área de investigação em que, pelo menos no Brasil, dominam as abordagens econômicas.

Agradeço aos colegas por terem aceito participar deste dossiê, trazendo contribuições relevantes para enriquecer o debate do tema na área da Sociologia.

Sonia K Guimarães

Porto Alegre, 17 de outubro, 2017.

Sonia Karan Guimarães é Professora titular do Departamento de Sociologia e do Programa de Pós-graduação em Sociologia, da Universidade Federal do Rio Grande do Sul (UFRGS), Brasil. \sonia21@ufrgs.br 


\section{Referências}

1. ALMEIDA, Mansueto; SCHNEIDER, Ben R. Globalization, Democratization, and the Challenges of Industrial Policy in Brazil, 2012. Disponivel em: http:// sistemas.mre.gov.br/kitweb/datafiles/IRBr/pt-br/file/CAD/LXII\%20CAD/Economia/ Almeida\%20\%20Schneider\%20612\%20v7.pdf. Acesso em 22 abr. 2016.

2. DEUTSCHMANN, Christoph. The Entrepreneur in Economic Sociology. In: SASE ANNUAL CONFERENCE, 15-19 jul. 2009, Paris. Panel I: Entrepreneurship and Socio-Economic Development. Paris: SASE, 2009.

3. ETZKOWITZ, Henry. The Triple Helix: University-Industry-Government Innovation in Action. Londres: Routledge, 2008.

4. GIBBONS, Michael et al. The New Production of Knowledge: The Dynamics of Science and Research in Contemporary Societies. Londres: Sage Publications, 1994.

5. GLOBAL Diversity and Inclusion: Fostering Innovation Through a Diverse Workforce. Forbes/Insights. Nova York: Forbes Media. jul. 2011. Disponível em: https://www.forbes.com/forbesinsights/innovation_diversity/index.html. Acesso em 16 out. 2017.

6. GUIMARÃES, Sonia K. Desenvolvimento econômico-social e instituições no Brasil. Civitas, Porto Alegre, v. 16, n. 2, p. 259-84, abr./jun., 2016.

7. GUIMARÃES, Sonia. K; AZAMBUJA, Lucas. R. Empreendedorismo high-tech no Brasil: condicionantes econômicos, políticos e culturais. Sociedade e Estado, Brasília, v. 25, p. 93-121, 2010.

8. NEFF, Gina, WISSINGER, Elizabeth; ZUKIN, Sharon. Entrepreneurial Labor among Cultural Producers: "Cool" Jobs in "Hot" Industries. Social Semiotics, v. 15, n. 3, p. 307-34, 2005. 